\title{
Política industrial,
}

\section{ventajas comparativas y crecimiento}

\section{Jaime Ros}

\section{Investigador}

Helen Kellogg Institute

for International Studies

Universidad de Notre Dame,

Indiana, Estados Unidos

Jaime.Ros.1@nd.edu
En este artículo se analizan las relaciones entre el patrón de especialización internacional y el crecimiento. Para ello se utiliza el marco analítico de la literatura reciente que pone de relieve la importancia de las condiciones iniciales y las políticas públicas, y no sólo de la dotación de factores. Asimismo, se examinan las implicaciones empíricas y de política económica de este enfoque. Tras una parte introductoria (sección I), se presenta en la sección II el marco analítico: un modelo con dos sectores de bienes transables en el ámbito internacional y un sector de insumos no transables en ese ámbito, con rendimientos crecientes a escala y externalidades pecuniarias dinámicas. En la sección III se derivan las implicaciones del análisis en términos de los efectos que pueden tener las políticas industriales sobre el patrón de especialización y el ritmo de crecimiento, mientras que en la sección IV se hace el mismo análisis respecto a los efectos de las condiciones iniciales y de las perturbaciones (shocks) reales y monetarias. En la sección V se examina la información empírica sobre las relaciones entre patrón de especialización, tasa de acumulación de capital y crecimiento. Y por último, en la sección VI se resumen las principales conclusiones del trabajo en lo que se refiere al alcance y las limitaciones de una política industrial. 


\section{I}

\section{Introducción}

En la literatura, vieja y nueva, sobre comercio internacional hay una lista de contribuciones que examinan en qué forma el patrón de especialización en el comercio internacional puede afectar el crecimiento -el argumento de la industria naciente, la tesis de Prebisch y Singer sobre la relación del intercambio de los productos primarios o los modelos multisectoriales con diferentes ritmos de aprendizaje en la nueva teoría del comercio internacional. Una característica común de estas contribuciones es que el patrón de especialización de una economía, tal y como está determinado por sus ventajas comparativas, puede ser distinto del patrón de especialización que aporta los mayores beneficios económicos de largo plazo. Esto puede ocurrir porque las ventajas comparativas estáticas de la economía no coinciden con sus ventajas comparativas dinámicas, por la presencia de externalidades tecnológicas asociadas con procesos de aprendizaje o porque la evolución de la relación del intercambio es tal que la economía se beneficiaría al abandonar el patrón de especialización asociado con las ventajas comparativas estáticas. En este caso, una política industrial que a través de subsidios o aranceles aduaneros reasigne recursos hacia los sectores con ventajas dinámicas, se justifica en presencia de fallas en los mercados de factores (en particular la ausencia de un mercado de capitales perfecto).

Existe otra manera de abordar el tema de cómo el patrón de especialización puede afectar la tasa de crecimiento de largo plazo, esto es, cuando una misma dotación de factores no determina un patrón de es- pecialización único y los distintos patrones de especialización consistentes con la misma dotación de factores tienen efectos dinámicos diferentes. Ello puede deberse a la existencia de externalidades pecuniarias dinámicas asociadas a diferentes eslabonamientos con los sectores de bienes no transables o imperfectamente transables en el mercado internacional. En este caso, no hay un conflicto entre ventajas comparativas estáticas y dinámicas que, en teoría, podría resolverse satisfactoriamente si el mercado de capitales fuese perfecto. Existe más bien una diferencia entre una muy alta rentabilidad del capital de un conjunto de inversiones coordinadas y la rentabilidad que puede obtener un inversionista individual y que es muy baja e insuficiente para desplazar capital hacia los sectores con alto potencial de crecimiento. El origen del problema, cuando la economía se especializa en el patrón menos dinámico, es entonces una falla de coordinación. Modelos recientes con este enfoque se encuentran en Rodrik (1995), Rodríguez-Clare (1996), Ciccone y Matsuyama (1996), Skott y Ros (1997) y Ros (2000, cap. 9). No parece necesario recalcar que el tema se vincula estrechamente con los debates sobre el papel que ha desempeñado la política industrial en las experiencias de crecimiento rápido en la posguerra, así como con la literatura empírica reciente sobre los efectos que el patrón de especialización en el comercio internacional tiene sobre el ritmo de crecimiento (Matsuyama, 1992; Sachs y Warner, 1997; Sala-iMartin, 1997).

\section{II \\ EI marco analítico}

En la teoría neoclásica, el patrón de especialización está determinado inequívocamente por la dotación de factores de la economía (junto con la tecnología y la relación del intercambio) puesto que, independientemente de las condiciones iniciales, la economía converge a un patrón de especialización que puede ser explicado por la dotación de factores. En el otro extre- mo del espectro teórico, algunos modelos de la nueva teoría del comercio internacional tratan el crecimiento de la productividad como el resultado de procesos de aprendizaje y dejan de lado la dotación de factores como determinante de la ventaja comparativa (por ejemplo, véase Krugman, 1987). En este caso, el patrón de especialización no puede determinarse con 
independencia de las condiciones iniciales y de la historia. Los accidentes - es decir, perturbaciones reales como un auge temporal de recursos naturales, o monetarias como una sobrevaluación cambiaria temporal- son decisivos en la determinación del patrón de especialización. La política industrial también se vuelve crucial en la adquisición de nuevas ventajas comparativas. El modelo que se presenta en esta sección puede verse como una extensión de un modelo neoclásico que admite la existencia de rendimientos crecientes a escala en la producción de insumos no transables, o bien, como un modelo de la nueva teoría del comercio internacional - como el de Krugman (1987) sobre las "consecuencias competitivas de Mrs. Thatcher"- que abandona el supuesto de una tecnología ricardiana e introduce bienes no transables. Como veremos, en estas condiciones, tanto la dotación de factores como las condiciones iniciales y las políticas tienen un papel que desempeñar en la determinación del patrón de especialización.

\section{El modelo básico}

Considérese una economía con tres sectores. El sector 1 produce un bien transable por medio de capital y trabajo, en condiciones competitivas y con rendimientos constantes a escala. El sector 2 produce también un bien transable, por medio de capital e insumos no transables (omitimos el factor trabajo para simplificar y hacer hincapié en que lo que produce este sector, en condiciones competitivas y rendimientos constantes a escala, es un bien que hace uso intensivo de capital). En ambos sectores la tecnología utilizada es CobbDouglas. El sector 3 es el productor de los insumos no transables. La producción de estos insumos se lleva a cabo por medio de trabajo y está sujeta a rendimientos crecientes a escala. Estos bienes intermedios pueden representar un conjunto de insumos manufacturados y servicios de producción (por ejemplo, servicios bancarios y seguros), como en el modelo de RodríguezClare (1996), o bien un conjunto de bienes y servicios de infraestructura (energía, transporte y comunicaciones), como en Skott y Ros (1997). Formalmente, el insumo I del conjunto de bienes intermedios $l i$ puede representarse como:

$$
I=\left(\Sigma(1 / n) I i^{\sigma}\right)^{1 / \sigma} \quad 0<\sigma<1,
$$

donde $n$ es el número de bienes intermedios, que se supone dado.
Alternativamente, se puede pensar en el sector 3 como una industria ensambladora de un conjunto de componentes li producidos bajo rendimientos crecientes: ${ }^{1}$

$$
I=n^{a}\left(\Sigma(1 / n) I i^{\sigma}\right)^{1 / \sigma} \quad a>1 \quad 0<\sigma<1,
$$

donde $/$ es la producción del sector 3 y $n$ es el número (no fijo) de componentes producidos. En este caso, interpretamos cada uno de estos componentes como un eslabón del proceso productivo. Un aumento en el número de componentes implica una división más fina del trabajo. Debido a la existencia de economías de especialización, esta mayor división del trabajo hace que éste sea más productivo, al incrementar la diferenciación y generar nuevos procesos e industrias auxiliares (véase Kaldor, 1967, p. 14). Hay dos diferencias entre esta especificación del sector 3 y la anterior. En primer lugar, las economías (de especialización) consideradas aquí son externas a la empresa, a diferencia de las economías de escala, internas a la planta, descritas en la primera especificación. Esto es lo que la segunda especificación implica: como el parámetro $a$ es superior a la unidad, un aumento de $x \%$ en el número de componentes, manteniendo (n li) constante, genera más unidades de $I$ que un aumento de $x \%$ en cada componente, manteniendo $n$ constante. En segundo lugar, en la actual especificación el número de bienes intermedios, en lugar de estar dado, es endógeno y está determinado por el tamaño del mercado para el sector 3 .

En lo que sigue, la presentación se basará en la primera especificación, caracterizada por la presencia de economías internas de escala, aunque se pueden derivar resultados cualitativamente similares con la segunda especificación. En cualquier caso, la diferencia clave entre los sectores 1 y 2 es que mientras el sector 2 tiene un eslabonamiento hacia atrás con el sector productor de insumos, no hay eslabonamientos en el caso del sector 1 . El sector integrado 2 y 3 puede verse como un "complejo productivo" caracterizado, como veremos, por efectos externos a cada uno de los dos sectores que lo componen.

a) Equilibrios múltiples y externalidades pecuniarias En una economía como la considerada existen, bajo ciertas condiciones, múltiples equilibrios de mercado. El análisis formal de la existencia de equilibrios múltiples

\footnotetext{
${ }^{1}$ Esta es la llamada especificación de Dixit-Stiglitz y Ethier (véase Ethier, 1982).
} 
se hace en el apéndice. Aquí nos limitamos a presentar la intuición. Para entender por qué existen equilibrios múltiples, conviene empezar por notar que un equilibrio en el que los sectores 1 y 2 coexisten es un equilibrio inestable. En efecto, imaginemos una economía en la que coexisten los dos sectores de bienes transables y hay una rentabilidad uniforme en ambos. A partir de esta situación, la reasignación de una pequeña dosis de capital hacia el sector 2 tiene el efecto de aumentar la rentabilidad relativa de él. En efecto, la ampliación del mercado para el sector 3 (asociada a la reasignación de capital hacia el sector 2) tiende a reducir los costos de producción de los bienes intermedios, con un efecto favorable en la tasa de beneficio del sector 2 . El aumento de la rentabilidad relativa del sector 2 hace que el capital fluya hacia él y refuerce por lo tanto el incremento de su tasa de beneficio. En cambio, una reasignación del acervo de capital hacia el sector 1 tiene el efecto opuesto de reducir la rentabilidad relativa del sector 2 , al disminuir el tamaño del mercado para el sector 3 y elevar los costos de producción de los bienes intermedios. El capital tiende entonces a fluir hacia el sector 1, reforzando el aumento de su rentabilidad relativa. En ambos casos el proceso continúa hasta la desaparición completa de uno de los dos sectores de bienes transables y la especialización completa de la economía en el otro sector.

Lo segundo que cabe hacer notar es que un equilibrio con especialización en el sector 1 siempre existe en la economía considerada, haya o no equilibrios múltiples. A niveles bajos de capital invertido en el sector 2, la rentabilidad en este sector tiende a cero, debido a los altos costos de producción de los bienes intermedios; en cambio, sigue siendo positiva en el sector 1, cualquiera sea el nivel del acervo de capital. Existen, por lo tanto, algunas asignaciones de capital, a niveles suficientemente bajos de capital invertido en el sector 2, en las cuales el sector 1 es más rentable que el sector 2. Como veremos más adelante, el hecho de que siempre exista un equilibrio con especialización en el sector 1 se debe al supuesto de que este sector no utiliza insumos producidos por el sector 3 .

Como siempre hay un equilibrio con especialización en el sector 1 , se sigue de ello que la existencia de un equilibrio con especialización en el sector 2 garantiza la existencia de equilibrios múltiples. Hay un equilibrio con especialización en el sector 2 si la rentabilidad de este sector, cuando todo el capital está invertido en él, es mayor que la del sector 1 (evaluada al salario de equilibrio de mercado cuando toda la fuerza de trabajo está empleada en el sector 3). Como se muestra en el Apéndice, la existencia de tal equilibrio depende de la dotación de capital y trabajo de la economía, así como de la relación del intercambio entre los sectores 1 y 2 . En particular, para que exista un equilibrio con especialización en el sector 2 , el acervo total de capital debe ser lo bastante grande como para que, cuando está invertido completamente en el sector 2 , los precios de los bienes intermedios sean lo suficientemente bajos y los salarios lo suficientemente altos como para que el sector 2 , que hace uso intensivo de capital e insumos, sea más rentable que el sector 1, que hace uso intensivo de trabajo. El valor del acervo de capital requerido para que haya equilibrios múltiples es mayor cuanto más alto sea el precio relativo de los bienes del sector 1 (respecto al sector 2), ya que ello eleva la rentabilidad relativa del sector 1 . Ese valor también aumenta con el número de empresas $n$ del sector de bienes intermedios que afecta adversamente la productividad del sector 3 y la rentabilidad del sector $2 .^{2}$

La existencia de equilibrios múltiples está asociada con la presencia de externalidades pecuniarias (aunque éstas no sean una condición suficiente, ya que puede haber un equilibrio único con especialización en el sector 1). En efecto, la existencia de rendimientos crecientes a escala en el sector de bienes intermedios implica que las decisiones de producción en el sector 3 y las decisiones de inversión en el sector 2 tienen efectos externos importantes. Un aumento de la producción de alguno de los bienes intermedios afecta adversamente la demanda de otros insumos, pero reduce el precio del conjunto de bienes intermedios y aumenta tanto el insumo total de bienes intermedios como la tasa de beneficio del sector 2. Además de estos efectos estáticos, existe una externalidad dinámica: una mayor rentabilidad del sector 2 estimula la acumulación de capital en este sector y conduce a un aumento de la demanda futura de bienes intermedios. Por el lado de la inversión, los productores atomizados del sector 2 toman todos los precios como dados y no consideran los efectos externos que el mayor acervo de capital tiene sobre la demanda futura de bienes interme-

\footnotetext{
${ }^{2}$ Esta conclusión no se aplica al modelo con la segunda especificación del sector 3, en la que el número de empresas es endógeno y afecta positivamente la productividad del sector.
} 
dios, ni la tendencia del precio de estos bienes a bajar al reducirse los costos de producción del sector 3 .

Como resultado de estas externalidades pecuniarias dinámicas, una economía especializada en el sector 1 quedará atrapada en este patrón de especialización si todas las empresas siguen un comportamiento que es individualmente racional. Debido a que el capital está invertido en el sector 1, la demanda de bienes intermedios es inexistente y los costos de producción de estos bienes son altísimos. En consecuencia, la rentabilidad del sector 2 es tan baja que el capital queda invertido en el sector 1. Esto mantiene altos los costos de producción del sector 3 y baja la rentabilidad del sector 2.

b) Los dos patrones de especialización comparados ¿Por qué importa si la economía queda atrapada en un patrón de comercio con especialización en el sector 1? Porque los dos patrones de especialización no son equivalentes en términos de bienestar económico (ni, como veremos más adelante, en términos de potencial de crecimiento). Como se muestra en el Apéndice, la existencia de múltiples equilibrios garantiza que la tasa de beneficio es mayor en el equilibrio con especialización en el sector 2 , a condición de que éste haga uso más intensivo de capital que el sector 1. Intuitivamente, el alto valor del acervo de capital necesario para que haya equilibrios múltiples genera salarios relativamente altos, los que tienden a deprimir la tasa de beneficio del sector 1 , que hace uso intensivo de trabajo. Por otra parte, el salario real, a niveles suficientemente altos del acervo de capital, también es mayor en el equilibrio con especialización en el sector 2. En efecto, a niveles suficientemente altos del acervo de capital, la mayor escala del sector 3 ha hecho a este sector más productivo y ha reducido el precio relativo de los bienes intermedios. Como resultado, a medida que aumenta el acervo de capital la relación capital/insumos intermedios en la producción del sector 2 tiende a reducirse, y la expansión del sector 2 a costa del sector 1 genera un exceso de demanda de trabajo con un impacto positivo sobre el salario real.

\section{Extensiones}

\section{a) El modelo con utilización de insumos en el sector 1}

En el modelo anterior, la tecnología disponible en el sector 1 no utiliza bienes intermedios. Supóngase ahora que el sector 1 utiliza bienes intermedios, aun- que menos intensivamente que el sector $2 .{ }^{3}$ La demanda de bienes intermedios ya no proviene exclusivamente del sector $2 \mathrm{y}$, por lo tanto, no depende solamente del acervo de capital invertido en él. El capital invertido en el sector 1 afecta ahora la demanda de bienes intermedios y, por ende, el precio relativo de estos bienes respecto de los producidos por el sector 2 . En consecuencia, la rentabilidad en el sector 2 dependerá ahora no sólo del capital invertido y del salario en ese sector, sino también del capital invertido en el sector 1 y, por lo tanto, del acervo total de capital. Lo anterior implica que existirá un valor suficientemente alto del acervo de capital que, cuando la totalidad de este acervo está invertido en el sector 1 , hará que el precio relativo de los bienes intermedios sea lo suficientemente bajo y el salario lo suficientemente alto como para que la tasa de beneficio en el sector 2 sea mayor que en el sector 1, evaluadas ambas tasas a los valores de equilibrio de mercado del salario y de los bienes intermedios. Cuando el acervo total de capital alcanza este valor, el equilibrio con especialización en el sector 1 desaparece, ya que el sector 2 es más rentable que el sector 1 aun cuando todo el capital esté invertido en este último. A diferencia del modelo anterior, ya no es cierto que existe siempre un equilibrio con especialización en el sector 1, cualquiera sea la dimensión del acervo total de capital.

Tenemos ahora tres configuraciones. Primero, para un rango de valores bajos del acervo de capital existe un equilibrio único. En este equilibrio la economía está especializada en la producción de bienes transables del sector $1 \mathrm{y}$ un pequeño sector 3 coexiste al lado del sector 1. La especialización en el comercio debe ser en el sector 1 , y no en el sector 2 , porque el sector 1 es el que usa los bienes intermedios menos intensivamente $\mathrm{y}$, por lo tanto, el único capaz de sobrevivir con los altos costos de producción que prevalecen en el sector de bienes intermedios.

En un rango de valores intermedios del acervo de capital existen dos equilibrios estables con especialización en el sector 1 y el sector 2, respectivamente. El tamaño del acervo total de capital es lo suficientemente grande como para generar un sector productivo de

\footnotetext{
${ }^{3}$ Este es el caso analizado por Rodríguez-Clare (1996), en un modelo similar al presentado en el Apéndice. Además de considerar la utilización de insumos intermedios en el sector 1, el modelo de Rodríguez-Clare adopta la especificación de Dixit-Stiglitz y Ethier para el sector 3 en lugar de la especificación con un número fijo de insumos intermedios.
} 
bienes intermedios y hacer al sector 2 viable, pero sólo si el capital está invertido en el sector 2. Si el capital está invertido en el sector 1, el mercado de bienes intermedios es insuficiente para que sea rentable invertir en el sector 2. Ahora bien, en el equilibrio con especialización en el sector 2 , la tasa de beneficio es mayor y el salario real es, al menos, igual de alto que en el equilibrio con especialización en el sector 1 . El equilibrio con especialización en el sector 2, por lo tanto, es superior en términos del criterio de Pareto al equilibrio con especialización en el sector 1, no sólo a partir de un cierto valor del acervo de capital sino para el rango completo de valores del acervo de capital en que existen equilibrios múltiples.

Finalmente, para valores grandes del acervo de capital, tenemos de nuevo un equilibrio único. El tamaño del acervo de capital es suficiente no sólo para hacer viable el sector 2 , sino también para hacer que el equilibrio con especialización en el sector 1 desaparezca. Los bajos precios de los bienes intermedios y los altos salarios hacen rentable para el inversionista individual desplazarse del sector 1 al sector 2 , aun cuando todo el capital esté inicialmente invertido en el sector 1. Al hacerlo, los precios de los bienes intermedios y los salarios se mueven de manera de reforzar la rentabilidad relativa del sector 2 y eventualmente la totalidad del capital se desplaza hacia este sector. El sector 1 se vuelve inviable, dados los altos salarios asocia- dos con la relación capital/trabajo relativamente alta de la economía.

b) El modelo con trabajo calificado en el sector de bienes intermedios

Supóngase ahora que la tecnología empleada en el sector 3 utiliza trabajo calificado (mientras que el sector 1 utiliza trabajo no calificado). ${ }^{4}$ Junto al tamaño del acervo de capital, el nivel de calificaciones de la fuerza de trabajo pasa entonces a influir en la existencia de equilibrios múltiples. En efecto, un mayor nivel de calificaciones puede compensar los altos costos que resultan de un mercado pequeño para los bienes intermedios producidos en condiciones de rendimientos crecientes y tiende, por lo tanto, a reducir el tamaño del acervo de capital requerido para que haya un equilibrio con especialización en el sector 2 . Se llega a conclusiones similares si es el sector 2, más que el sector 3, el que hace uso intensivo de trabajo calificado: mientras que el alto precio de los bienes intermedios tiende a deprimir la rentabilidad relativa del sector 2 , la abundancia de trabajo calificado tiende a aumentarla, de manera que el sector 2 puede ser viable dependiendo de la asignación del acervo de capital. En cualquier caso, la existencia de equilibrios múltiples puede resultar de diferentes combinaciones de niveles de calificación y acervos de capital, más que simplemente de un rango de valores intermedios del acervo de capital.

\section{III}

\section{Política industrial y crecimiento}

Muchos países en desarrollo han adoptado políticas industriales en un intento por acelerar el ritmo de industrialización y la tasa de crecimiento económico. Los resultados han sido mixtos, a juzgar por la variedad de ellos bajo políticas similares. Esto explica por qué la eficacia de esas políticas es controvertida y por qué hay distintas opiniones en torno a si estas políticas han significado alguna diferencia y, si éste es el caso, si sus efectos fueron positivos o negativos. Esta situación prevalece aun cuando tanto los observadores como los formuladores de políticas han documentado ampliamente el papel de la política industrial en el logro de una rápida industrialización en el este de Asia (véase Amsden, 1989; Wade, 1990). Explica en gran medida esta situación la ausencia de un consenso sobre la cuestión clave de cómo y en qué condiciones puede la política industrial alterar significativamente la tasa de acumulación de capital y de crecimiento. El marco analítico presentado más atrás arroja luz, como veremos, sobre esta cuestión.

Empecemos por hacer notar que en la teoría neoclásica del comercio internacional la dotación de factores, la tecnología y la relación del intercambio determinan de manera inequívoca el patrón de ventajas comparativas y de especialización de una economía. En cambio, en el marco analítico presentado en la sección anterior, la existencia de múltiples equili-

\footnotetext{
${ }^{4}$ Un caso similar es analizado por Rodrik (1995). En este análisis la existencia de equilibrios múltiples está asociada con un nivel relativamente alto de calificaciones de la fuerza de trabajo junto con un acervo de capital relativamente pequeño.
} 
brios de mercado asociados con distintos patrones de especialización, pero con la misma dotación de factores, tecnología y relación del intercambio, hace que la noción misma de ventaja comparativa se vuelva ambigua. Más precisamente, cuando un equilibrio único existe, sea éste con especialización en el sector 1 ó 2 , tiene sentido decir que la economía exhibe una ventaja comparativa en el sector correspondiente y los incentivos de mercado conducirán a que la economía se especialice en el sector que presenta una ventaja comparativa. Sin embargo, cuando existen múltiples equilibrios la pregunta de dónde se encuentra la ventaja comparativa en el comercio deja de tener una respuesta clara. Se puede decir (con una frase que no tendría ningún sentido en el marco de la teoría neoclásica) que la economía se encuentra en transición entre un patrón de ventajas comparativas que ha desaparecido y otro que aún no emerge.

Los distintos patrones de especialización consistentes con la misma dotación de factores tienen implicaciones dinámicas distintas. Considérese el modelo con insumos intermedios en los dos sectores de bienes transables y supóngase que las condiciones para la existencia de equilibrios múltiples se cumplen. Comparemos dos economías idénticas en todos los aspectos (dotación de factores, tasa de ahorro, tamaño de la fuerza de trabajo) excepto en su patrón de especialización. Una está especializada en el sector 1 y la otra lo está en el sector 2. Como hemos visto anteriormente, el salario real y la tasa de beneficio son mayores en la segunda economía. En consecuencia, esta economía también presenta un mayor ingreso per cápita; con la misma tasa de ahorro y de inversión, tiene entonces una mayor tasa de acumulación de capital y de crecimiento. La superioridad de la tasa de crecimiento de la economía especializada en el sector 2 es aun mayor en presencia de movilidad internacional de capital, ya que éste tenderá a fluir hacia la economía que ofrece la mayor rentabilidad al capital y, por lo tanto, su tasa de inversión tenderá a ser más alta.

Lo anterior significa que si una economía se encuentra especializada en el sector 1, una política industrial que reasigne recursos hacia los sectores 2 y 3 , conduciendo a un patrón de especialización basado en estos sectores, elevará la tasa de crecimiento de la economía. Más aun, a falta de política industrial la economía especializada en el sector 1 no se moverá espontáneamente hacia el equilibrio con alto crecimiento. Con los precios y salarios que prevalecen en el equilibrio con especialización en el sector 1, la tasa de beneficio del sector 2 es inferior a la del sector 1 y ningún inversionista individual encontrará rentable invertir en el sector 2. Los incentivos individuales, tal y como están mediados por el mercado, mantendrán a la economía en la trayectoria de bajo crecimiento asociada con la especialización en el sector 1, mientras este equilibrio siga existiendo. Sólo cuando una masa suficientemente grande de inversionistas se desplaza simultáneamente hacia los sectores 2 y 3 la rentabilidad en el sector 2 resulta más atractiva que la que se puede obtener en el sector 1 . Pero esto requiere de intervenciones de política para proveer la coordinación necesaria entre los productores.

Es cierto que, eventualmente, la economía especializada en el sector 1 obtendrá, mediante el propio proceso de acumulación de capital, una ventaja comparativa en el sector 2 . A partir de ese momento la rentabilidad del sector 2 será superior a la del sector $1 \mathrm{y}$ los incentivos de mercado llevarán a la economía a especializarse en el sector 2 , ya que el equilibrio con especialización en el sector 1 habrá desaparecido. Pero durante la transición hacia el acervo de capital necesario para que tal cosa ocurra, la economía inicialmente especializada en el sector 2 registrará una tasa de crecimiento más alta. El alto y sostenido ritmo de crecimiento de las economías del este asiático puede entenderse como el resultado de una sucesión de intervenciones de política que aceleraron las transiciones entre distintos patrones de producción y especialización en el comercio internacional. Es difícil imaginar cómo un modelo de desarrollo impulsado primariamente por las fuerzas de mercado, que inspira las recomendaciones actuales de política a los países en desarrollo, pueda haber "atravesado" esas transiciones tan exitosamente. No porque los éxitos basados en el mercado estén enteramente ausentes (esto se puede debatir), sino porque la teoría sugiere exactamente lo contrario: que los incentivos de mercado difícilmente pueden resolver con eficacia (o al menos con eficiencia) los problemas de coordinación que se presentan en la transición.

Las intervenciones exitosas de política orientadas a acelerar la transición son la base de la interpretación de Rodrik sobre cómo Corea y Taiwán se volvieron ricos (Rodrik, 1995; véase también Amsden, 1989, y Wade, 1990). El argumento es que, más que su orientación hacia la exportación, la característica distintiva de estas experiencias de crecimiento fue el aumento abrupto y sostenido de sus tasas de inversión a principios de los años sesenta. A través de una variedad de intervenciones de política, subsidiando y coordinando proyectos de inversión, la política gubernamental tuvo 
éxito en reasignar recursos a industrias modernas que hacían uso intensivo de capital y trabajo calificado. Con rendimientos crecientes en estas actividades, tal reasignación elevó la rentabilidad del capital y empujó a la economía hacia una trayectoria de alto crecimiento. La orientación hacia afuera fue una consecuencia, porque las mayores tasas de inversión incrementaron la demanda de bienes de capital importados. El nivel relativamente alto de calificación de la fuerza de trabajo en ambos países fue una condición para el éxito de la política industrial.

Al mismo tiempo, el análisis presentado muestra las limitaciones de la política industrial cuando las condiciones necesarias para su éxito (la existencia de equilibrios múltiples) están ausentes. Supóngase que en la economía existe un equilibrio único con especialización en el sector 1. En este caso, la política industrial no puede mejorar el resultado de las fuerzas del mercado. Considérese, por ejemplo, una política que intenta reasignar recursos hacia los sectores 2 y 3 . Supóngase que tal política tiene éxito en reasignar las nuevas inversiones hacia el sector 2. Precisamente porque no existe un equilibrio con especialización en el sector 2, el salario en esta economía caerá en comparación con su valor en el equilibrio con especialización en el sector 1. La rentabilidad también tenderá a caer, ya que el acervo de capital es pequeño y, en consecuencia, los costos de los bienes intermedios son altos. Con una tasa de beneficio en el sector 2 menor que la del sector 1 - evaluadas a los precios y salarios de mercado - los cambios inducidos en los precios relativos que son necesarios para hacer viable el sector 2 implicarían una caída aun mayor del salario real. Por otra parte, cuando existe un equilibrio único con especialización en el sector 2, la política industrial no se necesita. La economía tiene una clara ventaja comparativa en el sector 2 y los incentivos de mercado por sí solos conducen a la economía a adoptar el patrón de especialización que tiene la trayectoria de crecimiento más alto.

Lo anterior implica que la existencia de externalidades no es suficiente para justificar una política industrial. El hecho de que la política industrial no pueda hacer nada para mejorar el resultado del mercado (cuando sólo existe un equilibrio con especialización en el sector 1), o que sea innecesaria (cuando sólo existe un equilibrio con especialización en el sector 2) se debe en última instancia a que la presencia de externalidades estáticas y dinámicas, como lo vimos en la primera sección, no son suficientes para garantizar la existencia de equilibrios múltiples.

Este análisis tiene otras connotaciones interesantes. En la literatura sobre los efectos de la política industrial, la variedad de resultados se ha tendido a asociar con la variedad de políticas adoptadas (véase, por ejemplo, Amsden, 1989). Por ejemplo, el éxito de las políticas industriales en el este de Asia en comparación con el menos exitoso desempeño de América Latina se ha asociado con el hecho de que en el primer caso los estímulos a las empresas o sectores fueron otorgados a cambio del alcance de metas claramente definidas, y el horizonte temporal de operación de la política estuvo claramente circunscrito. Estas diferencias sin duda deben haber contribuido al éxito del modelo asiático. Pero nuestro análisis sugiere también que el éxito de una política industrial depende estrechamente de que estén dadas las condiciones necesarias. Una misma política industrial puede ser eficaz o no dependiendo de ello. En este contexto puede entenderse la importancia que tuvo el nivel inicial de calificación de la fuerza laboral en los países del este asiático para su despegue industrial de principios de los años sesenta. Ese nivel relativamente alto de calificación había existido durante largo tiempo, pero sólo se volvió crucial más adelante, al darle viabilidad a una política industrial que reasignó recursos hacia sectores modernos que hacían uso intensivo de capital físico y humano. Nuestro análisis permite entender también el papel desempeñado por el particular diseño de políticas industriales en el este de Asia. Al circunscribir el horizonte temporal y los estímulos, la política introdujo mecanismos de autocorrección. Si faltaban las condiciones necesarias para que la política industrial fuese eficaz, la falta de viabilidad de tal política se notaba claramente en cuanto se empezaba a aplicar. Esto permitía echar marcha atrás, minimizando el desperdicio de recursos involucrado en prolongar una política poco viable. 


\section{IV}

\section{Relación del intercambio y "enfermedad holandesa"}

El tamaño del acervo de capital y el nivel de calificaciones de la fuerza de trabajo no son los únicos factores que afectan la existencia de múltiples patrones de especialización. Como ya lo mencionamos, la existencia de múltiples equilibrios también depende de la relación del intercambio entre los bienes producidos por los sectores 1 y 2. Para ilustrar el papel de esa relación, considérese una economía especializada en el sector que hace uso intensivo de trabajo (sector 1) y supóngase que con el tiempo la entrada al mercado internacional de nuevos productores con bajos costos salariales tiende a reducir el precio relativo de los bienes intensivos en trabajo. Esto tiene el efecto de generar un equilibrio con especialización en el sector 2 sin que necesariamente haga que la economía se desplace hacia ese equilibrio con mayor crecimiento. En cierto modo, la economía está perdiendo su competitividad en el sector 1 , sin adquirir al mismo tiempo una ventaja comparativa en el sector 2. Esta situación puede describir las dificultades de varios países semi-industrializados que se enfrentan, por un lado, a la fuerte competencia de nuevos productores de bienes que hacen uso intensivo de trabajo con bajos salarios y, por otra parte, son todavía incapaces de competir con los productores más eficientes de bienes intensivos en capital de los países industrializados. Si interpretamos el sector 1 como un productor de bienes primarios, la transición describe los problemas de balanza de pagos y, eventualmente, el principio de la industrialización en países con abundancia de recursos naturales que enfrentan un deterioro de la relación de intercambio para sus exportaciones de productos primarios.

En cualquiera de estas interpretaciones, la economía en transición con una relación del intercambio que se ha vuelto desfavorable seguirá especializada en la producción de los bienes del sector 1 (productos primarios o bienes con uso intensivo de trabajo) hasta que eventualmente alcance los altos niveles de capital que hacen al sector 2 rentable desde el punto de vista del inversionista individual (a menos que de partida la caída del precio de los bienes del sector 1 sea tan grande que elimine el equilibrio con especialización en el sector 1). Ello es así simplemente porque el equilibrio con especialización en el sector 1 es un equilibrio localmente estable: ningún inversionista individual por sí solo encontrará las oportunidades de inversión en el sector 2 más atractivas que las existentes en el sector 1. En la transición, la economía sufrirá una reducción de su tasa de crecimiento como resultado de la disminución del precio relativo de los bienes del sector 1 . Como lo muestran las ecuaciones [7] y [14] en el Apéndice, la tasa de beneficio en esta economía es una función inversa del precio relativo de los bienes del sector 2. En la medida en que la tasa de acumulación dependa de la rentabilidad, la disminución del precio relativo de los bienes del sector 1 afectará adversamente la acumulación de capital y el crecimiento. La reducida tasa de acumulación prolongará a su vez la transición hacia el acervo de capital necesario para hacer que la producción de los bienes del sector 2 se vuelva espontáneamente rentable. Dada esta "trampa de lento crecimiento", una intervención de política económica puede hacer una diferencia sustancial en la tasa de crecimiento de mediano plazo.

Otra implicación del análisis confirma los temores presentes en la literatura sobre la "enfermedad holandesa" (véase una revisión de esta literatura en Corden, 1984). Supóngase que el sector 1 es intensivo en recursos naturales y que la economía está especializada en el sector 2. Con la relación del intercambio y el acervo de capital iniciales existen equilibrios múltiples. Partiendo de esta situación el precio relativo del bien 1 aumenta al punto de hacer que el sector 1 sea más rentable que el sector $2 \mathrm{y}$, por lo tanto, hace que desaparezca el equilibrio con especialización en el sector 2. Esto desplaza recursos de los sectores 2 y 3 hacia el sector 1 y la economía pasa a especializarse en el sector 1. Más adelante, el precio relativo del bien 1 vuelve a su nivel inicial, lo que hace reaparecer el equilibrio con especialización en el sector 2 . Sin embargo, los recursos no se desplazan hacia los sectores 2 y 3. La economía sigue especializada en el sector 1 ya que, como lo hemos supuesto, con la relación del intercambio inicial existen equilibrios múltiples $\mathrm{y}$, por lo tanto, la rentabilidad del sector 1 es mayor que la 
que un inversionista individual puede obtener en el sector 2 cuando la economía está especializada en el sector 1 . El auge de recursos naturales, aunque tem- poral, ha tenido efectos permanentes sobre el patrón de especialización de la economía y sobre la tasa de crecimiento a largo plazo.

\section{V}

\section{Evidencia empírica ${ }^{5}$}

\section{Especialización comercial y crecimiento}

La principal conclusión del análisis anterior es que el patrón de especialización es un factor determinante de la tasa de crecimiento económico. Existen dos canales a través de los cuales se da esta influencia. En primer lugar, controlando por otros factores, la rentabilidad del capital, y en consecuencia la tasa de inversión, tienden a ser mayores en el patrón de especialización basado en industrias con rendimientos crecientes. En segundo lugar, al mismo nivel de ingreso por trabajador, la especialización en industrias con rendimientos crecientes está asociada con una mayor relación producto/capital. Esto implica que, aun si la tasa de inversión fuera la misma, la tasa de acumulación de capital y de crecimiento será mayor cuando la economía se especializa en industrias con rendimientos crecientes. Pasamos ahora a examinar la validez empírica de estas relaciones.

Vale la pena observar, en primer lugar, que la reasignación de recursos hacia industrias modernas con uso intensivo de capital y trabajo calificado fue acompañada en la República de Corea y la provincia china de Taiwán, tal como lo predice nuestro marco analítico, por un aumento de la rentabilidad del capital (y también de la tasa de inversión). En la República de Corea, la tasa de beneficio en la industria manufacturera pasó de $16 \%$ en 1954-1956 a 28\% en 1957-1962 y a 35\% en 1963-1970 (Hong, 1993, citado por Rodrik, 1995). En la economía taiwanesa la rentabilidad aumentó después de fines de los años cincuenta en la mayoría de las industrias manufactureras, salvo en industrias tradicionales como las de textiles y madera (Lin, 1973, citado por Rodrik, 1995).

Veamos ahora la relación entre especialización y crecimiento en un análisis de corte transversal entre

${ }^{5}$ Esta sección se basa en parte en Ros (2000, cap. 9, secciones 3 y 4). países. Una primera cuestión es cómo medir el patrón de especialización. A medida que el nivel de ingreso de un país aumenta, el patrón de comercio cambia. Típicamente, la economía pasa de ser importadora neta de manufacturas a exportadora neta de manufacturas, y las manufacturas dominan crecientemente su comercio exterior. Como el nivel de ingreso afecta la tasa de crecimiento en formas que son independientes del patrón de especialización, nos gustaría tener un indicador de la especialización comercial que aísle los efectos de la dotación de recursos y de las políticas y excluya la influencia del nivel de ingreso sobre el patrón de comercio.

Tal indicador está disponible en Chenery y Syrquin (1986). Se trata de su índice de orientación comercial (OC) que mide el sesgo hacia las manufacturas en la composición de las exportaciones de mercancías después de ajustar por el nivel de ingreso y el tamaño de cada país. ${ }^{6}$ El índice mide entonces el grado en que una economía se especializa en las manufacturas como resultado de la influencia de factores distintos al tamaño y al ingreso (dotación de recursos y políticas). Se dispone de este índice para 1975 y para 34 países (contando a la región administrativa de Hong Kong y la provincia china de Taiwán), muchos de los cuales eran semi-industrializados en los años setenta. ${ }^{7}$

También consideraremos una muestra más pequeña de 22 países para los cuales están disponibles tanto el índice de orientación comercial como el índice de

\footnotetext{
${ }^{6}$ Esto es, mide, para un país dado, la desviación entre el sesgo observado hacia las manufacturas y el sesgo predicho en el caso de un país típico con un nivel de ingreso y tamaño similar. En Chenery y Syrquin (1986), el índice de orientación comercial mide el sesgo hacia las exportaciones primarias. Utilizamos este índice multiplicado por menos uno. Esto nos da el sesgo hacia las manufacturas. ${ }^{7}$ Argelia, Argentina, Brasil, Chile, Colombia, Costa de Marfil, Costa Rica, Ecuador, Egipto, España, Filipinas, Grecia, Guatemala, Hong Kong, Irak, Irán, Israel, Japón, Malasia, Marruecos, México, Perú, Portugal, República de Corea, República Dominicana, Singapur, Siria, Tailandia, Taiwán, Túnez, Turquía, Uruguay, Venezuela y Yugoslavia.
} 
Leamer de comercio intraindustrial y otras características del comercio exterior. Estos 22 países fueron agrupados de acuerdo con su índice de orientación comercial, de la siguiente manera:

i) países con un sesgo positivo hacia la exportación de manufacturas, principalmente del este asiático y Europa meridional: Egipto, España, Grecia, Hong Kong, Israel, Japón, Marruecos, Portugal, Singapur y Yugoslavia;

ii) países con un sesgo moderado hacia las exportaciones de bienes primarios, grupo que incluye principalmente a varios países latinoamericanos y del este asiático: Colombia, Costa Rica, Filipinas, Malasia, Tailandia y Turquía, y

iii) países con un fuerte sesgo hacia la exportación de bienes primarios, grupo que comprende principalmente países latinoamericanos: Argentina, Brasil, Costa de Marfil, Ecuador, Perú y la República Dominicana.

El cuadro 1 resume la información disponible para la muestra pequeña de 22 países; exhibe, para esta muestra, una relación positiva entre el sesgo hacia las manufacturas en la exportación y la tasa de inversión. El cuadro 2 presenta correlaciones de corte transversal entre países para esta misma muestra.

El cuadro 3 presenta correlaciones para la muestra grande de 34 países; el coeficiente de correlación entre el sesgo hacia las manufacturas y la tasa de inversión es de 0.35. Esta es exactamente la implicación de los modelos de la sección II, que sugieren que la especialización en industrias con rendimientos crecientes (un sesgo hacia las manufacturas) debe tener un efecto positivo sobre la tasa de inversión.
Otra implicación de esos modelos se refiere, como ya lo mencionamos, a los efectos del patrón de especialización sobre la tasa de acumulación de capital, dada la tasa de inversión. Como lo muestra el cuadro 2, la correlación entre el índice de orientación comercial (que mide el grado en que una economía se especializa en la exportación de manufacturas) y el crecimiento es muy alta (0.73), más alta que la correlación entre el índice de orientación comercial y la tasa de inversión. Vale la pena observar también el muy significativo coeficiente del índice de orientación comercial en una regresión de la tasa de crecimiento con este índice, la tasa de inversión y el nivel inicial de PIB por trabajador:

$$
g=\underset{(3.73)(4.02) \quad(4.39) \quad(-4.42)}{2.02+0.09 I / Y+1.47 O C-0.0002 Y / L_{60}} R^{2}=0.75
$$

siendo $g$ la tasa de crecimiento del PIB por trabajador (1960-1990); I/Y la tasa de inversión real (1970-1980); $O C$ el índice de orientación comercial de Chenery y Syrquin, 1975, e $Y / L_{60}$ el PIB real por trabajador en 1960. Las estadísticas $t$ aparecen entre paréntesis.

Esta ecuación indica que, a igualdad de ingreso inicial y tasa de inversión, los países que se especializan en la exportación de manufacturas crecieron durante el período 1960-1990 a una tasa mayor que los exportadores de productos primarios. Si interpretamos el sector 1 del modelo de la primera sección como un sector que hace uso intensivo de recursos naturales y tiene pocos eslabonamientos con actividades sujetas a rendimientos crecientes, la ecuación ilustra la implicación básica del modelo en términos de los efectos de la asignación de la inversión sobre el crecimiento. El nivel inicial del PIB por trabajador también tiene un

22 países: Orientación comercial, inversión y crecimientoa

\begin{tabular}{|c|c|c|c|}
\hline & \multirow[t]{2}{*}{$\begin{array}{c}\text { Sesgo hacia la exportación } \\
\text { de manufacturas }\end{array}$} & \multicolumn{2}{|c|}{$\begin{array}{c}\text { Sesgo hacia la exportación } \\
\text { de bienes }\end{array}$} \\
\hline & & Moderado & Fuerte \\
\hline Indice de orientación comercial 1975 & 0.45 & -0.10 & -0.45 \\
\hline Tasa de inversión & 24.8 & 19.1 & 19.5 \\
\hline Tasa de crecimiento & 4.1 & 2.8 & 1.5 \\
\hline Participación del comercio exterior & 84.8 & 48.5 & 39.2 \\
\hline Intensidad comercial (Leamer 1) & 0.08 & 0.04 & -0.05 \\
\hline Indice de comercio intraindustrial & 0.56 & 0.30 & 0.17 \\
\hline Número de países & 10 & 6 & 6 \\
\hline
\end{tabular}
(Promedios por grupo de países)

a Véanse definiciones y fuentes en el texto, y en las notas del cuadro 3. 


\begin{tabular}{|c|c|c|c|c|}
\hline & $\begin{array}{l}\text { Indice de orientación } \\
\text { comercial } 1975\end{array}$ & $\begin{array}{c}\text { Comercio } \\
\text { intraindustrial }\end{array}$ & $\begin{array}{l}\text { Intensidad } \\
\text { comercial }\end{array}$ & $\begin{array}{l}\text { Participación del } \\
\text { comercio exterior }\end{array}$ \\
\hline Indice de orientación comercial 1975 & 1.00 & 0.69 & 0.42 & 0.35 \\
\hline Comercio intraindustrial & & 1.00 & 0.73 & 0.71 \\
\hline Intensidad comercial & & & 1.00 & 0.85 \\
\hline Participación del comercio exterior & & & & 1.00 \\
\hline
\end{tabular}

a Véanse definiciones y fuentes en el texto, y en las notas del cuadro 3.

CUADRO 3

34 países: Correlaciones de corte transversal entre países

\begin{tabular}{|c|c|c|c|c|}
\hline & ${ }_{1975^{a}}$ & ${ }^{I / Y}{ }_{70-80}$ & $\begin{array}{c}\text { Participación del comercio } \\
\text { exterior }^{\mathrm{b}}\end{array}$ & Crecimiento $^{\mathrm{C}}$ \\
\hline $\mathrm{OC}_{1975}$ & 1.00 & 0.35 & 0.33 & 0.73 \\
\hline $\mathrm{I} / \mathrm{Y}_{70-80}{ }^{\mathrm{d}}$ & & 1.00 & 0.30 & 0.54 \\
\hline Participación del comercio exterior & & & 1.00 & 0.39 \\
\hline Crecimiento & & & & 1.00 \\
\hline
\end{tabular}

a OC $_{1975}$ : Indice de orientación comercial 1975 (Chenery y Syrquin, 1986).

b (Exportaciones + Importaciones) / PIB nominal. Promedio del período 1970-1980 (Penn World Table, Mark 5.6).

c Crecimiento: tasa de crecimiento del PIB real por trabajador 1960-1990 (Penn World Table, Mark 5.6).

Comercio intraindustrial: índice de comercio intraindustrial 1982 (Leamer, 1988). Intensidad comercial: índice de intensidad comercial ajustada 1982, Leamer 1 (Leamer, 1988).

d I/Y $70-80$ : Participación de la inversión en el PIB. Promedio del período 1970-1980 (Penn World Table, Mark 5.6).

coeficiente muy significativo ( $y$ negativo) en la regresión. Esto sugiere que en este grupo de 34 países semiindustriales se tendía a la convergencia: a igualdad de otras condiciones, los países con un menor nivel de ingreso tendían a crecer más rápidamente. Sin embargo, como indican los modelos examinados anteriormente, la convergencia estaba condicionada por el patrón de especialización: las economías especializadas en la exportación de manufacturas convergían hacia niveles altos de ingreso a una tasa mayor que las economías especializadas en la exportación de productos primarios. Estaban en realidad convergiendo hacia un nivel de ingreso de equilibrio más alto, como lo sugiere el análisis efectuado en la sección II.

Vale la pena observar que los resultados que se presentan aquí tienden a confirmar las conclusiones de trabajos recientes (Sachs y Warner, 1997; Sala-i-Martin, 1997) que muestran que, controlando por otras variables, las economías especializadas en la producción y exportación de bienes que hacen uso intensivo de recursos naturales tienden a crecer más lentamente que las economías especializadas en la exportación de manufacturas. Según Sachs y Warner la abundancia de recursos naturales, medida por las exportaciones que hacen uso intensivo de recursos naturales como porcentaje del PIB, tiene un efecto negativo en el crecimiento, una influencia que los autores atribuyen a efectos del tipo "enfermedad holandesa". Dichos autores experimentan con otras medidas de la abundancia de recursos naturales (como la participación de las exportaciones de bienes primarios en las exportaciones totales o la cantidad de tierra per cápita) con resultados que confirman esa relación negativa. Según Sala-i-Martin, las exportaciones de productos primarios como fracción de las exportaciones totales es una de las pocas variables económicas que está sistemáticamente correlacionada con el crecimiento (con un signo negativo).

\section{Apertura al comercio, inversión y crecimiento}

En su "análisis de sensibilidad" de las regresiones de corte transversal de crecimiento, Levine y Renelt (1992) examinaron la solidez de las relaciones empíricas entre el crecimiento a largo plazo y una variedad de indicadores económicos, políticos e institucionales. Su evaluación concluyó de manera pesimista. Aunque hay muchas especificaciones econométricas en las que varios indicadores están significativamente correla- 
cionados con las tasas de crecimiento per cápita, casi todas estas especificaciones son frágiles en el sentido de que pequeñas alteraciones en las 'otras' variables explicativas modifican los resultados previos. Sólo dos relaciones pasan la prueba. Una es la correlación positiva entre el crecimiento y la tasa de inversión (la inversión como porcentaje del PIB). La segunda es la correlación positiva entre la participación del comercio exterior en el PIB y la tasa de inversión. El cuadro 3 presenta, para nuestra muestra grande de 34 países, resultados que apoyan esas conclusiones: la correlación positiva entre crecimiento y tasa de inversión $(0.54)$ y aquella entre participación del comercio exterior y tasa de inversión (0.30).

El primer resultado es reconfortante, pues concuerda con la teoría económica. El segundo es un rompecabezas. En primer lugar, es importante subrayar que la relación robusta encontrada por Levine y Renelt no es entre tasa de inversión y barreras al comercio, sino entre tasa de inversión y participación del comercio exterior. Las relaciones entre la tasa de inversión, o alternativamente la tasa de crecimiento, y varios indicadores de barreras comerciales o distorsiones en la política de comercio exterior no son robustas. ${ }^{8}$ Por lo tanto, la relación robusta no parece reflejar los efectos de la política comercial. En segundo lugar, cuando se controla por la tasa de inversión, no existe relación robusta entre participación del comercio exterior y crecimiento (esto es así, por cierto, si el indicador es la participación de las exportaciones, la de las importaciones o la de la suma de las dos). El hecho de que la correlación robusta es entre comercio y tasa de inversión sugiere que si el comercio afecta al crecimiento lo hace no a través de los canales convencionales que envuelven la asignación de recursos sino a través de canales menos convencionales que involucran efectos positivos sobre la tasa de inversión.

Cuáles pueden ser estos canales es algo que no está claro en la literatura existente. Romer (1990 a y b) sugiere que la apertura al comercio tiene un efecto positivo en los gastos de investigación y desarrollo y, al incrementar así el ritmo de cambio tecnológico, influye en la tasa de inversión y el crecimiento. Otros puntos de vista destacan los efectos positivos de la

\footnotetext{
${ }^{8}$ Estos indicadores incluyen la "distorsión del tipo de cambio real" de Dollar (1992), la prima promedio en el mercado negro de divisas, y el índice de apertura comercial de Chenery y Syrquin. En una revisión de la literatura más reciente (posterior al artículo de Levine y Renelt) sobre política comercial y crecimiento, Rodríguez y Rodrik (1999) concluyen que los indicadores de política comercial carecen de significación estadística en regresiones de crecimiento de corte transversal bien especificadas.
}

apertura al comercio sobre la transferencia de tecnología. ${ }^{9}$ Cualesquiera que sean los méritos de estas opiniones, difícilmente constituyen una explicación convincente del resultado de Levine y Renelt. Una razón es que la apertura al comercio en estos modelos no se refiere a la participación del comercio y, por lo tanto, para proveer una explicación de la relación estadística entre participación del comercio y tasa de inversión enfrentan una vieja objeción recientemente replanteada por De Long y Summers (1991). La participación del comercio está influenciada por el tamaño de un país y su proximidad a sus socios comerciales. Si Bélgica y los Países Bajos se fusionaran, sería difícil imaginar cuánto habría de reducirse (o aumentar) el ritmo combinado de progreso técnico, en virtud de que esta nueva entidad sería menos "abierta" que cada uno de los dos países por separado. ${ }^{10}$

Aun si la objeción a medir la apertura al comercio por la participación del comercio no fuera decisiva, la pregunta sigue en pie: ¿A qué se debe que la correlación robusta se dé sólo entre inversión y participación en el comercio y no entre inversión y otras medidas (más apropiadas) de la apertura al comercio? El análisis presentado en esta sección y en secciones anteriores sugiere varias hipótesis que pueden aportar una explicación convincente de la relación positiva entre la participación del comercio y la tasa de inversión. ${ }^{11}$ Nuestra línea de argumentación será que la explicación del nexo entre comercio e inversión involucra al patrón de especialización tal y como está

\footnotetext{
${ }^{9} \mathrm{Al}$ mismo tiempo, es posible argumentar que los efectos de la apertura al comercio dependen del patrón de especialización que la mayor apertura induzca (como en el modelo de la sección II). En algunos modelos norte-sur, como el de Young (1991), la apertura al comercio puede incluso resultar en un menor ritmo de cambio tecnológico en el sur. Además, la inversión extranjera directa es un vehículo mayor de transferencia de tecnología y no hay una relación clara entre apertura al comercio y apertura a la inversión extranjera directa.

${ }^{10}$ Cabe señalar que la observación de De Long y Summers no es una objeción a modelos en los que la apertura al comercio - en el sentido de ausencia de barreras comerciales- tiene un efecto positivo sobre la inversión. Se trata, más bien, de una objeción a la utilización de la participación del comercio exterior en el PIB como medida de la apertura al comercio. La implicación, sin embargo, es que no debemos interpretar la correlación entre inversión y participación del comercio como prueba que apoya modelos en los que la apertura estimula la inversión.

${ }^{11}$ Ya hemos mencionado el argumento de Rodrik (1995) según el cual una mayor tasa de inversión puede conducir a una mayor participación del comercio como resultado del aumento en las importaciones de bienes de capital en economías en proceso de industrialización. En este argumento, la causalidad va de inversión a comercio y no a la inversa. Nuestra atención en lo que sigue irá en una dirección distinta que complementa a la anterior.
} 
determinado por políticas y por la dotación de factores, incluyendo la de recursos naturales. Los estudios sobre diferencias de tasas de crecimiento entre países han hecho caso omiso de estos vínculos porque, con algunas excepciones recientes, han descuidado el influjo de esos dos factores (política industrial y dotación de recursos) a través de sus efectos sobre la orientación comercial. ${ }^{12}$

El núcleo del argumento es que la correlación positiva entre la participación del comercio y la tasa de inversión está mediada por la orientación del comercio; es decir, la explicación de la relación positiva es que la participación del comercio y la tasa de inversión están ambas afectadas positivamente por un sesgo hacia las manufacturas en la orientación comercial. Ya hemos examinado e ilustrado los efectos de la orientación comercial sobre la tasa de inversión. Consideremos ahora los efectos de la orientación comercial sobre la participación del comercio. El cuadro 1 muestra una relación positiva entre estas dos variables. Los cuadros 2 y 3 muestran coeficientes de correlación positivos de 0.35 y 0.33 .

¿Por qué un patrón de especialización basado en la exportación de manufacturas habría de afectar positivamente la participación del comercio? Una razón es el efecto positivo que la especialización en actividades sujetas a rendimientos crecientes puede tener en la creación de comercio. Los rendimientos crecientes son favorables a la expansión del comercio intraindustrial -corrientes de comercio en dos sentidos de productos

\section{VI}

\section{Conclusiones}

Este trabajo ofrece un marco analítico para pensar las relaciones entre patrón de especialización y crecimiento, y también evidencia empírica que de hecho sugiere que el patrón de especialización es un factor determinante de importancia en el proceso de crecimiento. El análisis puso de relieve el alcance y las limitaciones de una política industrial. Por un lado, mostró cómo una política industrial que reasigne recursos hacia sectores con potencial para explotar economías de escala

\footnotetext{
${ }^{12}$ Las excepciones incluyen, como ya lo mencionamos, a Sachs y Warner (1997) y Sala-i-Martin (1997).
}

similares, sujetos a economías de especialización. Los países con un sesgo mayor hacia las manufacturas en sus exportaciones suelen presentar mayores índices de comercio intraindustrial. El coeficiente de correlación entre los dos índices, como se muestra en el cuadro 2, es de 0.69 .

Una segunda razón puede ser la presencia de efectos de tipo "enfermedad holandesa" de las exportaciones de productos primarios. Lo que implican los modelos de "enfermedad holandesa" es que los países que exportan productos primarios tienden a ser menos abiertos, a igualdad de otras condiciones, ya que en equilibrio de largo plazo tienen sectores de bienes no transables mayores (véase Ros, 2000, cap. 8). A este respecto, cabe señalar que la orientación comercial hacia las manufacturas muestra una relación positiva con el índice de apertura al comercio de Leamer. Este es un índice de intensidad comercial ajustado que representa la diferencia entre el nivel observado de comercio (a diferencia del patrón de comercio) y el nivel predicho por un modelo HeckscherOhlin, que incluye dotación de factores así como distancia a los mercados. La relación positiva con la orientación comercial indica que mientras más sesgado está el patrón de comercio hacia las exportaciones de productos primarios, menor tiende a ser el índice de intensidad comercial, probablemente como resultado de la existencia de sectores más grandes de bienes no transables junto con niveles menores de comercio intraindustrial.

y de especialización puede elevar la tasa de crecimiento de una economía a través del aumento de la rentabilidad del capital y de la tasa de acumulación del mismo. Por otro lado, dejó en claro que la eficacia de la política industrial depende de la presencia de ciertas condiciones - sobre todo de una dotación de capital físico y humano y un mercado suficientemente amplio para sectores con economías de escala y de especialización- que permitan, en efecto, que la reasignación de recursos eleve la tasa de beneficio en los nuevos sectores líderes.

El análisis empírico tendió a confirmar que economías orientadas a la exportación de manufacturas 
tienden a crecer más rápidamente que aquellas orientadas a las exportaciones primarias. Entre los países semi-industrializados no hay experiencias de supercrecimiento basadas en la exportación de bienes que hacen uso intensivo de recursos naturales..$^{13}$ Lo anterior no significa que países con abundancia de tales recursos deban modificar su patrón de especialización para crecer más rápidamente. Un esfuerzo en este sentido probablemente fracasaría en muchos de ellos, precisamente porque la eficacia de la política industrial está condicionada por la dotación de factores. Tampoco significa lo anterior que esos países con abundantes recursos naturales estén condenados a crecer más lentamente que los países con sesgo hacia la exportación de manufacturas, ya que pueden acelerar su pro- ceso de crecimiento actuando sobre otros determinantes de ese proceso.

Cabe destacar, por último, que en este artículo las implicaciones de política económica están circunscritas por el tipo de externalidades consideradas. Los efectos externos de tipo pecuniario y dinámico que se dan entre los productores de bienes con uso intensivo de capital y los productores de bienes intermedios que operan en condiciones de rendimientos crecientes generan fallas de coordinación que necesitan de la intervención pública para ser superadas. Sin embargo, el trabajo no abordó otro tipo de externalidades y fallas de mercado (en particular en los mercados de factores) que justifican intervenciones generalmente incluidas bajo el rubro de política industrial.

\section{Apéndice: El modelo formal ${ }^{14}$}

Existen en la economía dos sectores productores de bienes transables (indicados por 1 y 2). La tecnología en los dos sectores es Cobb-Douglas:

$$
Q_{1}=K_{1}^{b} L_{1}{ }^{l-\mathrm{b}} \quad Q_{2}=K_{2}{ }^{a} I^{l-a}
$$

donde $K$ es el insumo de capital y $L$ el insumo de trabajo. Suponemos que $a>b$, es decir, el sector 2 hace uso más intensivo de capital que el sector 1 . I representa el insumo de un conjunto de bienes intermedios:

$$
I=\left(\Sigma(1 / n) I i^{\sigma}\right)^{1 / \sigma} \quad 0<\sigma<1,
$$

donde $n$ es el número de bienes intermedios que se supone dado. El sector que produce estos bienes intermedios (sector 3) lo hace utilizando trabajo en condiciones de rendimientos crecientes a escala:

$$
I_{i}=L_{i}^{1+\mu} \quad \mu>0
$$

donde $L_{\mathrm{i}}$ es el insumo de trabajo.

Las empresas en los tres sectores maximizan beneficios, tomando los precios de los insumos como dados. Las empresas en los sectores 1 y 2 también toman como dados los

\footnotetext{
${ }^{13}$ Botswana, aunque difícilmente puede catalogarse como una economía semiindustrializada, es lo que más se acerca a una excepción. El proceso sostenido de crecimiento de esta economía parece haber sido el resultado de una sucesión de auges mineros (explotación de diamantes) en el marco de una política macroeconómica estable.

${ }^{14}$ Este Apéndice se basa en Ros (2000), capítulos 5 (secciones 2 y 3), 8 (sección 3) y 9 (sección 1).
}

precios de los bienes producidos. En ambos sectores el acervo de capital está predeterminado. De las condiciones de primer orden para la maximización de beneficios se derivan los niveles de empleo de los factores variables a corto plazo:

$$
\begin{aligned}
& L_{1}=\left[(1-b) p_{1} / w\right]^{1 / b} K_{1} \\
& I=(1-a)^{1 / a}\left(p_{3} / p_{2}\right)^{-1 / a} K
\end{aligned}
$$

donde $w$ es el salario, $p_{1}$ y $p_{2}$ son los precios de los bienes 1 y 2 , y $p_{3}$ es el costo (mínimo) de una canasta de bienes intermedios tal que $\mathrm{I}=1$.

En el sector 3, los productores operan en condiciones de competencia monopolística y enfrentan curvas de demanda con pendiente negativa:

$$
I_{i}^{d}=D p_{i}^{-\eta} \quad \eta>1
$$

donde $D$ refleja la posición de la curva de demanda y $\eta$ es la elasticidad precio de la demanda que enfrentan los productores individuales. Esta elasticidad es una función de $\sigma, a, \mathrm{y} n$, y para $n$ grande está dada aproximadamente por $1 /(1-\sigma)$. La desigualdad en [4] es consecuencia de las restricciones paramétricas $0<a<1$ y $0<\sigma<1$.

A partir de la función de demanda en [4] y de la función de producción [1], la decisión de precio óptima de un productor individual de bienes intermedios es un margen de ganancia $(\pi)$ sobre costo marginal $(\omega)$ :

donde:

$$
p_{i}=(1+\pi) \omega
$$

$$
1+\pi=[\eta /(\eta-1)] \quad \omega=w /(1+\mu) I i^{\mu /(1+\mu)}
$$


Las ecuaciones [4] y [5] se combinan con la demanda de insumos del sector 2 (ecuación [3]) a fin de encontrar una solución para $I, p_{3}$ y $D$. Utilizando [1] y la solución para $I$ se obtiene el nivel de empleo en el sector 3 :

$$
\begin{gathered}
L_{3}=\left[(1 / n)^{1-f} G K_{2}^{a} p_{2} / w\right]^{1 / f} \\
G=(1-a)(1+\mu)(\eta-1) / \eta \\
f=a-\mu(1-a)
\end{gathered}
$$

\section{El equilibrio en el mercado de trabajo}

El equilibrio en el mercado de trabajo implica una tasa de salario uniforme en los sectores 1 y 3 , así como el pleno empleo de la fuerza de trabajo (L): $\mathrm{L}=\mathrm{L}_{1}+\mathrm{L}_{3}$. Considérese lo que sucede con el salario de equilibrio cuando el capital se reasigna del sector 1 al sector 2 . Al nivel inicial del salario, la reducción del acervo de capital en el sector 1 causa una caída de la demanda de trabajo en ese sector. Utilizando la ecuación de demanda de trabajo para $\mathrm{L}_{1}$, y manteniendo el salario constante, la reducción del empleo en el sector 1 está dada por:

$$
-\mathrm{dL}_{1}=\left[(1-\mathrm{b}) \mathrm{p}_{1} / \mathrm{w}\right]^{1 / \mathrm{b}}\left(-\mathrm{dK}_{1}\right)
$$

El mayor acervo de capital en el sector 2 causa un aumento de la demanda de trabajo en el sector 3. Utilizando la función de demanda para $\mathrm{L}_{3}$, el aumento del empleo en el sector 3 al nivel inicial de salario es:

$$
\mathrm{dL}_{3}=\left[(1 / \mathrm{n})^{1-\mathrm{f}} \mathrm{G} \mathrm{p}_{2} / \mathrm{w}\right]^{1 / \mathrm{f}}(\mathrm{a} / \mathrm{f}) \mathrm{K}_{2}^{(\mathrm{a} / \mathrm{f})-1} \mathrm{dK}_{2}
$$

con $-d K_{1}=d K_{2}$, por el supuesto de que la reasignación deja intacto el acervo total de capital. Que el cambio dé lugar a exceso de oferta o de demanda de trabajo depende del tamaño de $\left(-d L_{1}\right)$ comparado con $\left(d L_{3}\right)$. Claramente la respuesta depende del nivel de $K_{2}$. Cuando $K_{2}$ es pequeño, el sector 3 también es pequeño y produce a costos muy altos, dada la presencia de economías de escala en este sector. Siendo el precio relativo de los insumos intermedios $\left(p_{3} / p_{2}\right)$ muy alto, la intensidad de capital $(K / I)$ en el sector 2 es también muy alta a pesar de que el valor absoluto de $K_{2}$ es pequeño. Con un valor alto de la relación $(K / I)$, el aumento del acervo de capital en el sector 2 tiene efectos indirectos pequeños sobre el empleo del sector 3. La reducción de la demanda de trabajo en el sector 1 es entonces mayor que el aumento de la demanda de trabajo en el sector 3. Una reasignación de capital del sector 1 al sector 2 tiende entonces a crear un exceso de oferta de trabajo y ello requiere una disminución del salario para despejar el mercado de trabajo.
En cambio, cuando el nivel de $K_{2}$ es alto, los efectos indirectos sobre el empleo de la expansión del sector 2 pueden contrarrestar la reducción de la demanda de trabajo en el sector 1. La mayor escala del sector 3 ha hecho de éste un sector más productivo y ha reducido el precio relativo de los bienes intermedios. Con una intensidad de capital $(K / I)$ más pequeña, la expansión del sector 2 a costa del sector 1 puede entonces tener el efecto de generar un exceso de demanda de trabajo y de aumentar el salario de equilibrio.

Podemos verificar formalmente que una reasignación del capital hacia el sector 2 debe tener primero el efecto de reducir el salario de equilibrio y más adelante el efecto de aumentarlo. Sustituyendo las funciones de demanda de trabajo en la condición de pleno empleo, podemos derivar un locus de equilibrio del mercado de trabajo que muestra el salario de equilibrio bajo diferentes composiciones del acervo de capital. Manteniendo K constante, la pendiente de este locus en espacio $\left(\log w, \log K_{2}\right)$ es:

$d \log w / d \log K_{2}=\left[a / f-\left(K_{2} / K_{1}\right)\left(L_{1} / L_{3}\right)\right] /\left[1 / f+(1 / b)\left(L_{1} / L_{3}\right)\right]$

donde $L_{1} / L_{3}$, usando las funciones de demanda de trabajo, está dado por:

$$
\begin{gathered}
\mathrm{L}_{1} / \mathrm{L}_{3}=\left(\mathrm{B} \mathrm{K}_{1} / \mathrm{A} \mathrm{K}_{2}^{\mathrm{a} / \mathrm{f}}\right) \mathrm{w}^{1 / \mathrm{f}-1 / \mathrm{b}} \\
B=\left[(1-b) p_{1}\right]^{1 / b} \quad A=\left[(1 / n)^{1-f} G p_{2}\right]^{1 / f}
\end{gathered}
$$

Como se puede verificar, la pendiente de este locus es negativa, tendiendo a cero, a niveles bajos de $K_{2}$ y se vuelve positiva, tendiendo a " $a$ ", a niveles altos de $K_{2}$ (a condición de que tales valores altos existan dado el tamaño del acervo total de capital). Por lo tanto, el valor de equilibrio del salario primero se reduce a medida que $K_{2}$ aumenta y eventualmente aumenta, volviéndose una función creciente de $K_{2}$ (véase el gráfico 1 ).

\section{El equilibrio en el mercado de capital}

Utilizando la definición de la tasa de beneficio y las condiciones de primer orden para la maximización de beneficios en los sectores 1 y 2 , las rentabilidades en estos sectores pueden expresarse como funciones inversas de la tasa de salario:

$$
\begin{aligned}
& r_{1}=b\left(p_{1} / p_{2}\right)\left[(1-b) p_{1} / w\right]^{(1-b) / b} \\
& r_{2}=a K_{2}^{\mu(1-a) / f}\left[(1 / n) G /\left(w / p_{2}\right)\right]^{(1-f) / f}
\end{aligned}
$$

El capital es móvil entre los sectores 1 y 2 . El equilibrio en el mercado de capital requiere el pleno empleo del 
GRAFICO 1

\section{El patrón de especialización bajo rendimientos crecientes}

A

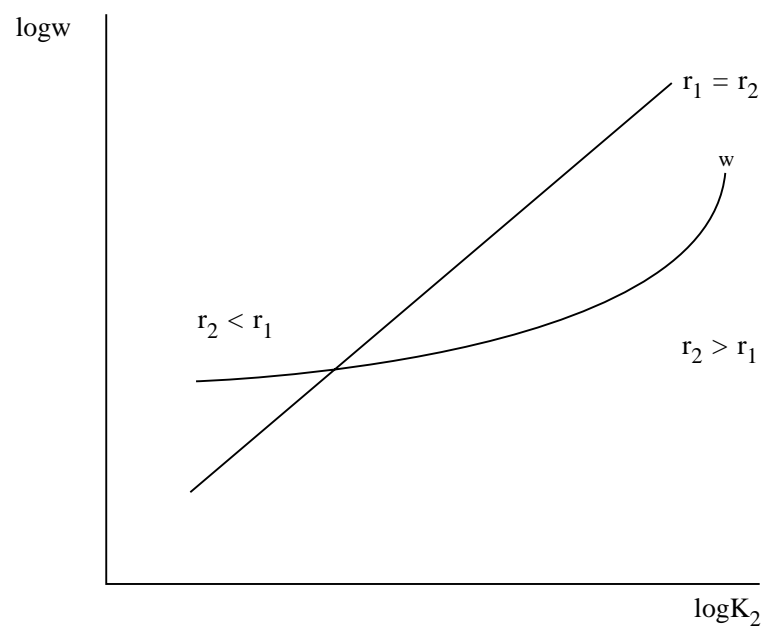

B

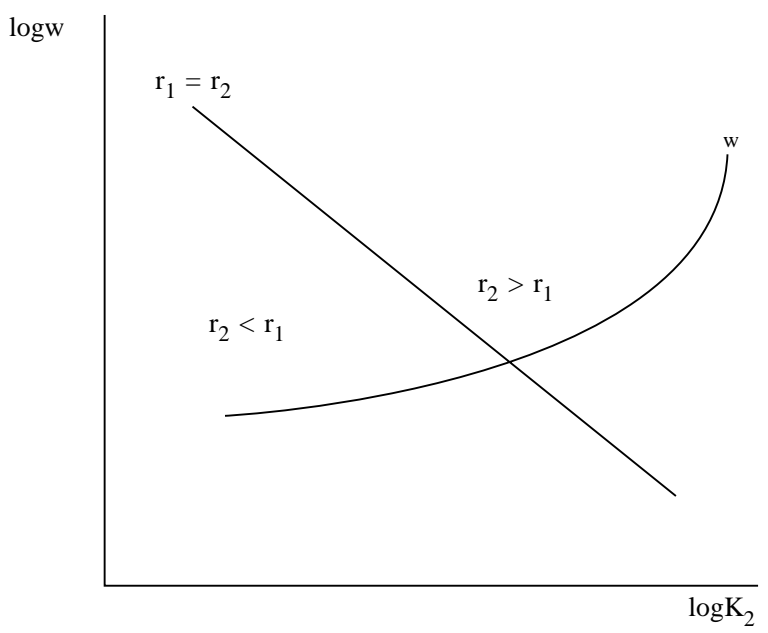

acervo total de capital $(K)$ y la igualdad de las tasas de beneficio en los dos sectores que usan capital (en la medida en que estos dos sectores coexisten):

$$
K=K_{1}+K_{2} \quad r_{1}=r_{2}
$$

Sustituyendo las expresiones de la tasa de beneficio en la condición de igualdad entre las dos tasas, podemos derivar la ecuación de un locus del equilibrio en el mercado de capital. En espacio $\left(w, K_{2}\right)$, este locus muestra, para cada valor dado del salario, el valor de $K_{2}$, y la correspondiente composición del acervo de capital, que arroja la misma tasa de beneficio en los sectores 1 y 2 . Ante un aumento en el salario ¿cómo debe cambiar la composición del acervo de capital para que se mantenga el equilibrio en el mercado de capital? Intuitivamente, la respuesta a esta pregunta depende de cuál de los dos sectores hace uso más intensivo de trabajo. El mayor salario tenderá a reducir en mayor medida la tasa de beneficio del sector con uso más intensivo de trabajo. La reasignación requerida dependería entonces de los efectos de $K_{2}$ en las rentabilidades relativas. ${ }^{15}$ El problema es que no está claro en este modelo cuál de los dos sectores hace uso más intensivo de trabajo directa e indirectamente.

\footnotetext{
${ }^{15} \mathrm{Si}$ no hay ningún efecto, es decir si $K_{2}$ no aparece en la ecuación de la tasa de beneficio del sector 2 , no habrá ninguna reasignación que sea capaz de restaurar la igualdad de las tasas de beneficio. El locus sería entonces una recta horizontal al valor único del salario que es consistente con la igualdad de las tasas de beneficio. Como se puede verificar, éste es el caso si $\mu=0$, es decir, si la tecnología del sector integrado 2 y 3 exhibe rendimientos constantes a escala.
}

Aunque en el sector 2 el uso de capital es más intensivo que en el sector 1 (en el sentido que $a>b$ ), el parámetro de rendimientos crecientes $(\mu)$ puede ser lo suficientemente grande para hacer que la participación "indirecta" del trabajo en el sector 2 sea mayor que la participación del trabajo en el sector 1. Ello se debe a la presencia de rendimientos a escala en el sector 3 , que hace que la suma de las participaciones del capital y del trabajo en el sector "integrado" 2 y 3 sea mayor que la unidad.

Formalmente, la pendiente del locus de equilibrio en el mercado de capital en espacio $\left(\log w, \log K_{2}\right)$ está dada por:

$$
d \log w / d \log K_{2}=[\mu(1-a) / f] /[(1-a)(1+\mu) / f-(1-b) / b]
$$

Tenemos, en efecto, dos casos, dependiendo de los parámetros de la tecnología en los tres sectores. En el gráfico 1 , sección A, se muestra el caso en que $b>f$. Ello implica que $(1-a)(1+\mu)>(1-b)$, es decir, que la participación "indirecta" del trabajo en el sector 2 es mayor que la participación del trabajo en el sector 1. En este caso, un aumento del salario (dado $K_{2}$ ) reduce la tasa de beneficio en el sector 2 más de lo que lo hace en el sector 1 . Se requiere entonces un aumento en $\mathrm{K}_{2}$ (que afecta positivamente a $r_{2}$ ) para restaurar la igualdad de tasas de beneficio. Esto significa que la pendiente del locus es positiva.

En el segundo caso (gráfico 1, sección B), tenemos que $b<f$. Esto implica: $(1-a)(1+\mu)<(1-b)$, es decir, la participación "indirecta" del trabajo en el sector 2 es menor que la participación del trabajo en el sector 1 . Un aumento del salario (dado $K_{2}$ ) reducirá entonces la rentabilidad del sector 1 
en mayor medida que la del sector 2. Ello requiere una redución en $K_{2}$ (que reduce $r_{2}$ ) para restaurar la igualdad de tasas de beneficio. La pendiente del locus es entonces negativa.

En las dos configuraciones mostradas en el gráfico 1, la región a la derecha del locus $r_{1}=r_{2}$ es tal que el sector 2 es más rentable que el sector 1 . Ello se debe a que es una región en que $K_{2}$ es relativamente grande, para cada nivel dado de salario, y $K_{2}$ tiene un efecto positivo sobre la rentabilidad relativa del sector 2 . De esta manera, a la derecha del locus el capital fluirá hacia el sector 2 y la relación $K_{2} / K_{1}$ tenderá a aumentar. En cambio, a la izquierda del locus $r_{1}=r_{2}$, la rentabilidad del sector 2 es menor que la del sector 1 y el capital fluirá hacia el sector 1 . De lo anterior se sigue que en ambos casos la composición del acervo de capital correspondiente a la intersección de los dos locus es un equilibrio inestable. Como se muestra en el gráfico, una asignación del acervo de capital con un nivel de $\mathrm{K}_{2}$ mayor que en la intersección genera una tasa de beneficio en el sector 2 que es mayor que la del sector 1 . El capital se desplaza entonces hacia el sector 2 y deprime en mayor medida la rentabilidad relativa del sector 1 . Mecanismos similares, en sentido contrario, operan para asignaciones de capital con menos $K_{2}$ que en la intersección. ${ }^{16}$

\section{Equilibrios múltiples}

Podemos verificar también que cuando las dos curvas se intersectan esta intersección es única. ${ }^{17}$ En consecuencia, si una intersección existe habrá dos equilibrios estables en los que el acervo de capital estará invertido por completo en uno de los dos sectores. En un equilibrio, la economía está completamente especializada en el sector 1 . Como en este caso no existe un sector 3, no sólo el acervo de capital sino la totalidad de la fuerza de trabajo se encuentra empleada en el sector 1. En el otro equilibrio, la economía se especializa en la producción y exportación del bien 2 y, como no existe sector 1, la totalidad de la fuerza de trabajo se encuentra empleada en el sector 3 .

\footnotetext{
${ }^{16}$ La inestabilidad de la asignación de capital correspondiente a la intersección se debe a la presencia de rendimientos crecientes a escala en el sector integrado 2 y 3 . Bajo rendimientos constantes a escala, el locus del equilibrio en el mercado de trabajo tiene pendiente negativa (si el sector integrado 2 y 3 es el sector intensivo en capital) y el locus del equilibrio en el mercado de capital es una recta horizontal (véase la nota de pie de página anterior). Como el lector lo puede verificar, el equilibrio correspondiente a la intersección es estable en este caso.

${ }^{17}$ En el caso A, ello es porque el locus del equilibrio del mercado de capital tiene una mayor pendiente que el locus del equilibrio en el mercado de trabajo a niveles altos de $K_{2}$. Las condiciones necesarias y suficientes para ello son que a $>$ b y f $>0$. En el caso $B$, la intersección es única porque el locus del mercado de capital tiene una mayor pendiente, a niveles bajos de $K_{2}$, que el locus del mercado de trabajo.
}

En nuestra economía un equilibrio con especialización en el sector 1 siempre existe, haya o no equilibrios múltiples. Como lo mencionamos en el texto, esto se debe al supuesto de que el sector 1 no utiliza insumos intermedios producidos bajo rendimientos crecientes. A niveles bajos de $K_{2}$, la tasa de beneficio del sector 2 tiende a cero, mientras que se mantiene positiva en el sector 1 no importa cuán grande sea el acervo de capital. Existen, por lo tanto, asignaciones de capital a niveles suficientemente bajos de $K_{2}$ para las cuales el sector 1 es más rentable que el sector 2 .

Como un equilibrio con especialización en el sector 1 siempre existe, se sigue que la existencia de un equilibrio con especialización en el sector 2 garantiza la existencia de una intersección y, por lo tanto, garantiza la existencia de equilibrios múltiples. A su vez, un equilibrio con especialización en el sector 2 existe si la rentabilidad del sector 2, cuando la totalidad del acervo de capital está invertida en este sector, es mayor que la del sector 1 (evaluada al salario de equilibrio de mercado correspondiente a $L=L_{3}$ ). Consideremos en primer lugar el salario en la especialización en el sector $2\left(w_{2}^{*}\right)$. Usando [6] y las condiciones $L_{3}=L$ y $K_{2}=K$, y resolviendo para el salario, tenemos:

$$
w_{2}^{*}=G(1 / n)^{1-f} p_{2} K^{a} / L^{f}
$$

Sustituyendo [9] en [8], igualando $w_{2} *$ a $w_{2}$ y $K_{2}$ a $K$, obtenemos la tasa de beneficio en el equilibrio con especialización en el sector $2\left(r_{2}{ }^{*}\right)$ :

$$
r_{2}^{*}=a(L / n)^{1-f} / K^{1-a}
$$

La tasa de beneficio en el sector 1, evaluada al salario $w_{2}{ }^{*}$, se obtiene de la sustitución de [9] en [7]:

$$
r_{2}{ }^{l}=b\left(p_{1} / p_{2}\right)^{1 / b}\left[(1-b) n^{l-f} L^{f} / G K^{a}\right]^{(1-b) / b}
$$

Nótese que la tasa de beneficio del sector 1, evaluada con el salario $w_{2}{ }^{*}, r_{2}{ }^{1}$, es una función creciente del número de productores de bienes intermedios $(n)$. Un mayor número de productores incrementa el costo unitario de cada uno de los bienes intermedios y reduce la demanda de trabajo en el sector 3. Ello tiene un efecto negativo sobre $w_{2}{ }^{*} \mathrm{y}$, por lo tanto, tiende a aumentar la tasa de beneficio en el sector 1 que no utiliza bienes intermedios. Este efecto negativo sobre el salario se ve contrarrestado en el caso de la tasa de beneficio del sector 2, ya que un mayor número de productores implica costos mayores en el sector $2: r_{2} *$ es una función decreciente del número de productores $(n)$.

Utilizando [10] y [11], la condición para que $r^{*}>r_{2}{ }^{l}$ y, por lo tanto, para la existencia de equilibrios múltiples es:

$$
K^{a-b}>K^{* a-b}=(b / a)^{b}\left(p_{1} / p_{2}\right)[(1-b) / G]^{1-b} n^{1-f} L^{f-b}[12]
$$


La existencia de equilibrios múltiples depende de la dotación de capital y trabajo y de los precios relativos. En particular, el acervo total de capital debe ser lo suficientemente grande para que, cuando la totalidad de este acervo se invierte en el sector 2 , el precio de los bienes intermedios sea lo suficientemente bajo para hacer viable a este sector. El valor crítico $\left(K^{*}\right)$ del acervo total de capital aumenta con el precio relativo $\left(p_{1} / p_{2}\right)$, que incrementa la rentabilidad del sector 1. También aumenta con el número de empresas $(n)$ en el sector 3 , que afecta adversamente la rentabilidad del sector 2. El efecto del tamaño de la fuerza de trabajo sobre el valor crítico del acervo de capital depende del signo de $(f-b)$, es decir de la participación "indirecta" del trabajo en el sector 2 comparada con la del sector 1 .

Supongamos que se cumple la condición para la existencia de equilibrios múltiples y comparemos los salarios y las tasas de beneficio en los dos equilibrios. En el equilibrio con especialización en el sector 2, el salario y la tasa de beneficio están dados por las ecuaciones [9] y [10]. En el equilibrio con especialización en el sector 1, tenemos $K_{1}=K$ y $L_{1}=L$. Utilizando las ecuaciones [2] y [7], el salario y la tasa de beneficio en el equilibrio con especialización en el sector 1 son:

$$
\begin{gathered}
w_{1}^{*}=(1-b) p_{1}(K / L)^{b} \\
r_{1}^{*}=b\left(p_{1} / p_{2}\right)(L / K)^{1-b}
\end{gathered}
$$

La comparación de [10] y [14] muestra que $r_{2} *$ es mayor que $r_{1}^{*}$ si:

$$
\mathrm{K}^{\mathrm{a}-\mathrm{b}}>\mathrm{K}^{* * \mathrm{a}-\mathrm{b}}=(\mathrm{b} / \mathrm{a})\left(\mathrm{p}_{1} / \mathrm{p}_{2}\right) \mathrm{n}^{1-\mathrm{f}} \mathrm{L}^{\mathrm{f}-\mathrm{b}}
$$

Comparando [12] y [15] podemos establecer que $K^{*}>K^{* *}$. El supuesto $a>b$ y la condición de segundo orden para un máximo entre los productores de bienes intermedios garantizan esta desigualdad. ${ }^{18}$ En consecuencia, cuando un equilibrio con especialización en el sector 2 existe $\left(K>K^{*}\right)$, la rentabilidad en este equilibrio es mayor que en el equilibrio con especialización en el sector 1 (ya que $K$ es entonces mayor que $\left.K^{* *}\right)$.

Un examen de [9] y [13] muestra que para que $w_{2}{ }^{*}$ sea mayor que $w_{1}{ }^{*}$, el acervo de capital total debe ser tal que:

$$
K^{\mathrm{a}-\mathrm{b}}>K^{* * * \mathrm{a}-\mathrm{b}}=(1-b)\left(p_{1} / p_{2}\right) n^{1-f} L^{f-b} / G
$$

A partir de [12] y [16], podemos establecer que $K^{* * *}>K^{*} .19$ La existencia de un equilibrio con especialización en el sector 2 no garantiza que el salario en este equilibrio sea mayor que en el equilibrio con especialización en el sector 1. Ello requiere que el acervo de capital sea mayor que $K^{* * *}$. En este caso, con $K>K^{* * *}$, y por lo tanto con $K$ mayor que $K^{*}$ y $K^{* *}$, existe un equilibrio con especialización en el sector 2 que presenta tanto una tasa de beneficio como un salario mayores que en el equilibrio con especialización en el sector 1.
${ }^{18} K^{*}>K^{* *}$ si la siguiente condición se cumple:

$$
(1-b) / b>[(1-a) / a](1+\mu)(1-1 / \eta)
$$

$a>b$ implica que $(1-b) / b>(1-a) / a$. Para que se cumpla la condición de segundo orden para la maximización de beneficios entre los productores de bienes intermedios, es necesario que $(1+\mu)$ $(1-1 / \eta)<1$. Juntas, estas desigualdades garantizan el cumplimiento de la condición más arriba.
${ }^{19}$ Esto requiere como en el caso anterior:

$$
(1-b) / b>[(1-a) / a](1+\mu)(1-1 / \eta)
$$

Esta desigualdad está garantizada por las condiciones ya mencionadas $(a>b$ y la condición de segundo orden para la maximización de beneficios entre los productores de bienes intermedios). 
Amsden, A. (1989): Asia's Next Giant: South Korea and Late Industrialization, Nueva York, Oxford University Press.

Chenery, H. B. y M. Syrquin (1975): Patterns of Development, 19501970, Londres, Oxford University Press.

_ (1986): The semi-industrial countries, H. B. Chenery, S. Robinson y M. Syrquin, Industrialization and Growth. A Comparative Study, Washington, D.C., Banco Mundial.

Ciccone, A. y K. Matsuyama (1996): Start-up costs and pecuniary externalities as barriers to economic development, Journal of Development Economics, vol. 49, No 1, Amsterdam, Países Bajos, Elsevier Science Publishers, B.V.

Corden, W. M. (1984): Booming sector and Dutch disease economics: Survey and consolidation, Oxford Economic Papers, vol. 36, No 3, Londres, Oxford University Press.

De Long, J. B. y L. Summers (1991): Equipment investment and economic growth, Quarterly Journal of Economics, vol. 106, $\mathrm{N}^{\circ}$ 2, Cambridge, Massachusetts, The MIT Press.

Dollar, D. (1992): Outward-oriented developing economies really do grow more rapidly: Evidence from 95 LDCs 1976-1985, Economic Development and Cultural Change, vol. 40, $\mathrm{N}^{\circ} 3$, Chicago, Illinois, The University of Chicago.

Ethier, W. J. (1982): National and international returns to scale in the modern theory of international trade, American Economic Review, vol. 72, $\mathrm{N}^{\circ} 3$, Nashville, Tennessee, American Economic Association.

Hong, W. (1993): Trade and development: The experience of Korea and Taiwan, en G. Hasson (ed.), International Trade and Development, Londres, Routledge.

Kaldor, N. (1967): Strategic Factors in Economic Development, The Frank W. Pierce Memorial Lectures at Cornell University, October 1966, Ithaca, Nueva York, Cornell University.

Krugman, P. (1987): The narrow moving band, the Dutch disease, and the competitive consequences of Mrs. Thatcher: Notes on trade in the presence of dynamic scale economies, Journal of Development Economics, vol. 27, № 1-2, Amsterdam, Países Bajos, Elsevier Science Publishers, B.V.

Leamer, E. (1988): Measures of openness, en R. Baldwin (ed.), Trade Policy Issues and Empirical Analysis, NBER Conference Report Series, Chicago, Illinois, University of Chicago Press.

Levine, R. y D. Renelt (1992): A sensitivity analysis of cross-country growth regressions, American Economic Review, vol. 82, $\mathrm{N}^{\circ} 4$, Washington, D.C., American Economic Association.
Lin, C. (1973): Industrialization in Taiwan, 1946-72: Trade and Import Substitution Policies in Developing Countries, Nueva York, Praeger.

Matsuyama, K. (1992): Agricultural productivity, comparative advantage and economic growth, Journal of Economic Theory, $N^{\circ}$ 58, Nueva York, Academic Press.

Rodríguez-Clare, A. (1996): The division of labor and economic development, Journal of Development Economics, vol. 49, $\mathrm{N}^{\circ} 1$, Amsterdam, Países Bajos, Elsevier Science Publishers, B.V.

Rodríguez, F. y D. Rodrik (1999): Trade policy and economic growth: A skeptic's guide to the cross national evidence, NBER working paper, $N^{\circ} 7081$, Cambridge, Massachusetts, National Bureau of Economic Research (NBER ).

Rodrik, D. (1995): Getting interventions right: How South Korea and Taiwan grew rich, Economic Policy, $\mathrm{N}^{\circ} 20$, Londres, Centre for Economic Research, abril.

Romer, P. (1990a): Capital, labor and productivity, Brookings papers on economic activity, Special issue, Washington D.C., The Brookings Institution.

(1990b): Endogenous technological change, Journal of Political Economy, vol. 98, $\mathrm{N}^{\circ}$ 5, Chicago, Illinois, The University of Chicago Press.

Ros, J. (2000): Development Theory and the Economics of Growth, Michigan, University of Michigan Press.

Sachs, J. D. y A. M. Warner (1997): Natural Resource Abundance and Economic Growth, Cambridge, Massachusetts, Harvard Institute for International Development.

Sala-i-Martin, X. (1997): I just ran two million regressions, American Economic Review, vol. 87, № 1, Washington, D.C., American Economic Association, mayo.

Skott, P. y J. Ros (1997): The 'big push' in an open economy with non-tradable inputs, Journal of Post Keynesian Economics, vol. 20, Armonk, Nueva York, M.E. Sharpe Inc. (p. 5).

Young, A. (1991): Learning by doing and the dynamic effects of international trade, Quarterly Journal of Economics, vol. 106, $\mathrm{N}^{\circ} 2$, Cambridge, Massachusetts, MIT Press.

Wade, R. (1990): Governing the Market: Economic Theory and the Role of Government in East Asian Industrialization, Princeton, New Jersey, Princeton University Press. 